\title{
Formation of intermetallic $\delta$ phase in Al-10Si-0.3Fe alloy investigated by in-situ 4D X-ray synchrotron tomography
}

\author{
J.M. Yu ${ }^{1}$, N. Wanderka ${ }^{1, *}$, A. Rack ${ }^{2}$, R. Daudin ${ }^{3}$, E. Boller ${ }^{2}$, H. Markötter ${ }^{1}$, A. Manzoni ${ }^{1}$, \\ F. Vogel ${ }^{1}$, T. Arlt ${ }^{1}$, I. Manke ${ }^{1}$, J. Banhart ${ }^{1}$ \\ ${ }^{1}$ Helmholtz-Zentrum Berlin für Materialien und Energie GmbH, Hahn-Meitner-Platz 1, \\ 14109 Berlin, Germany \\ ${ }^{2}$ European Synchrotron Radiation Facility, 71 Avenue des Martyrs, 38000 Grenoble, France \\ ${ }^{3}$ Univ. Grenoble Alpes, CNRS, SIMaP, F-38000 Grenoble, France
}

Keywords: intermetallic phases; synchrotron X-ray tomography; in-situ experiment; $\mathrm{Al}-\mathrm{Si}$ alloy, Al-Si-Fe phase

\begin{abstract}
During solidification of Fe-containing Al-Si casting alloys, various different intermetallic phases are formed. As this can have an impact on mechanical properties we investigated phase formation by applying in-situ time resolved synchrotron X-ray tomography. For a commercially pure $\mathrm{Al}$ - 10Si - 0.3 wt.\%Fe alloy, phase morphology and spatial arrangement during solidification was revealed with $1^{\circ} \mathrm{C}$ temperature resolution. We find that many of the intermetallic phases that have been identified as $\beta$-AlFeSi phases in previous studies are in fact $\delta$ phases. It was found that $\delta$ plates mainly nucleate on the eutectic $\mathrm{Al}$ and $\mathrm{Si}$. $\delta$ phase formation terminates almost simultaneously with the final solidification of eutectic phases. Features of $\delta$ phase growth such as impingement, branching and deformation of plates are discussed. The phase separation sequence during solidification is described and explained by the existence of "cells" of residual liquid in which $\delta$ phase formation progresses rapidly due to the supersaturation of solute atoms.
\end{abstract}

\footnotetext{
*corresponding author: N. Wanderka

e-mail: wanderka@helmholtz-berlin.de, Tel.: +49-30-806242079
} 


\section{Introduction}

The formation of the intermetallic $\beta$ phase in Al-xSi ( $\mathrm{x}=5 \div 30 \mathrm{wt} . \%$ ) - based alloys has been the subject of numerous studies [1-3]. It is well known that the size and density of the $\beta$ phase strongly depends on the amount of Fe in an alloy. Fe is a natural impurity and its removal from primary aluminium is very costly. Therefore, many studies focus on how to reduce the size and density of the $\beta$ phase in the corresponding alloys [4-6]. Coarse intermetallic phases are often detrimental to mechanical properties. This makes it crucial to understand under which conditions which phase is formed.

In order to be able to tailor phase formation, an understanding of the nucleation and growth mechanisms of the $\beta$ phase is mandatory. Since the dimensions of the $\beta$ phases range up to several hundreds of micrometres, analytical methods that can cover this length scale are required. The morphology of $\alpha-\mathrm{Al}_{8} \mathrm{Fe}_{2} \mathrm{Si}$ and other phases in a solidified Al-10Si-0.1Fe alloy with 200 ppm Sr addition were visualized using focus ion beam (FIB) tomography [7]. A further insight into the formation of morphology and the spatial arrangement of intermetallic phases in an Al-Si-Cu-Fe (W319) alloy was gained using X-ray synchrotron tomography [8]. Such ex-situ techniques were applied only after solidification when the formation of phases had already been completed. A more profound understanding of the linkage between processing, in particular solidification, and phase formation requires a complete mapping of the evolution of phase formation.

In-situ synchrotron X-ray tomography has become an important tool to explore such processes in 4D (3D + time) due to the high intensity of synchrotron X-ray beams that lead to short exposure times and high spatial resolution. $\beta$ phase formation during solidification of an Al-Si-Fe alloy was recently investigated by in-situ synchrotron X-ray tomography $[9,10]$. While it was suggested that the most abundant nucleation site for the $\beta$ phase is the surface oxide, further nucleation mechanisms for the $\beta$ phase were proposed: Nucleation on or near $\alpha$ $\mathrm{Al}$ dendrites, nucleation on pre-existing $\beta$ phases (auto-nucleation), and nucleation on the oxide skin of pores $[9,10]$.

The intermetallic $\beta$ phase is not the only phase present in Al-Si-based alloys. In fact, there are various types of intermetallic phases that differ by their chemical composition and morphology [11-13]. Both chemical composition and morphology are a source of confusion when it comes to distinguish between intermetallic phases in Al-Si-based alloys. For example, $\mathrm{Yu}$ et al. recently reported a specific intermetallic $\gamma$ phase which exhibits the Chinese script morphology characteristic for the $\alpha-\mathrm{Al}_{8} \mathrm{Fe}_{2} \mathrm{Si}$ phase but has a composition similar to the $\beta$ phase [14]. Moreover, the intermetallic $\delta-\mathrm{Al}_{4} \mathrm{FeSi}_{2}$ phase shows a plate-like morphology similar to that of the $\beta$ phase but has a different composition. Therefore, assessing the identity 
of a phase by considering only its morphology or its composition can lead to misinterpretations.

The $\delta$ phase is usually found in Al-Si alloys with high Si content [13, 15-17] and/or containing modifier additions such as $\operatorname{Sr}[7,16,18]$. It was proposed that the $\delta$ phase is the dominant phase at high Si contents and high cooling rates, while the $\beta$ phase is dominant at high Fe contents and low cooling rates $[13,15,17]$. The $\beta$ phase can nucleate via binary or ternary eutectic reactions depending on the Fe content of the alloy. $\beta$ phase formation via a binary reaction was observed in an Al-Si alloy with 0.7 wt.\% Fe, while the $\beta$ phase was found to form via a ternary reaction in an alloy containing only $0.3 \mathrm{wt} . \% \mathrm{Fe}$ [1]. Recently, Wang et al. [19] and Puncreobutr et al. [9] observed the formation of $\beta$ in a binary reaction by in-situ synchrotron X-ray tomography.

Unlike the $\beta-\mathrm{Al}_{5} \mathrm{FeSi}$ phase, the $\delta-\mathrm{Al}_{4} \mathrm{FeSi}_{2}$ phase is rarely reported even in $\mathrm{Al}-\mathrm{Si}$ alloys with relatively low Fe content ( $\leq 0.3 \mathrm{wt}$.\%) although one would expect it. This is most likely due to a similar plate-like morphology and a close chemical composition of both phases which renders it difficult to distinguish between the two as demonstrated by SEM/EDS [20]. Thus, it is easy to incorrectly identify the $\delta$ phase as $\beta$ phase especially when utilizing ex-situ microscopic methods that do not reveal the 3D morphology and environment of the phase and the time evolution of phase formation.

In this study, in-situ 4D synchrotron X-ray tomography was used to characterize the evolution of the microstructure of an Al-10Si-0.3Fe-based alloy during solidification in order to gain new insights into the mechanisms of the formation of intermetallic phases and in particular the $\delta$ phase.

\section{Experimental}

\subsection{Material}

An Al-10Si-0.3Fe (wt.\%) alloy was manufactured by Hydro Aluminium, Germany, from pure alloying elements that were mixed, melted and cast into a cylindrical permanent mould of $30 \mathrm{~mm}$ diameter and $200 \mathrm{~mm}$ height. The solidification rate was $\sim 8{ }^{\circ} \mathrm{C} / \mathrm{s}$ in the centre of the sample. The chemical composition of the alloy was measured by optical emission spectrometry and is listed in Table 1.

For in-situ synchrotron X-ray tomography experiments, cylindrical samples of $3.2 \mathrm{~mm}$ length and $\sim 1.5 \mathrm{~mm}$ diameter were machined from the centre of the castings. 


\subsection{In-situ synchrotron X-ray tomography}

In-situ synchrotron X-ray tomography experiments were performed at the beamline ID 19 of the European Synchrotron Radiation Facility (ESRF), Grenoble, France to image density, morphology, location and interconnection of intermetallic phases during solidification. The experimental set-up is shown in Fig. 1 and is similar to that described in Ref. [21].

A designated electrical resistance furnace with two amorphous carbon windows on each side that let the X-ray beam pass was used to heat and melt the samples. The cylindrical specimen was fixed to the top of an alumina rod using zirconia paste and inserted into the furnace through an opening at the bottom of the furnace. The rod was then connected to the rotating stage.

The mounted sample was first heated to $666^{\circ} \mathrm{C}$ at $20^{\circ} \mathrm{C} / \mathrm{min}$ and then held for $5 \mathrm{~min}$ at this temperature to ensure complete melting and homogenization. While the stage was rotating, the sample was cooled down to $449^{\circ} \mathrm{C}$ at a rate of $1{ }^{\circ} \mathrm{C} / \mathrm{min}$, during which tomograms were acquired continuously. During melting and solidification, the sample's stability was maintained by its native oxide skin so that no container was needed. The low cooling rate ensured a slow enough evolution of the microstructure during tomogram acquisition and a low level of image blurring and artefacts. The entire cooling process took 217 min during which an equal number of high-resolution tomographic scans were performed.

The tomographic scans were performed at a beam energy of $\sim 18 \mathrm{keV}$ by recording 1000 projections covering an angular range of $180^{\circ}$. The total time for a full $180^{\circ}$ scan and returning of the rotation stage to its original orientation was about $60 \mathrm{~s}$, which lead to a temperature difference of $1{ }^{\circ} \mathrm{C}$ between two successive complete tomograms. The readout area of the PCO-Dimax CMOS camera was set to $1632 \times 1632$ pixels. The camera was coupled to a ten times magnifying optic resulting in a pixel size of $1.1 \mu \mathrm{m}$ and therefore a total volume of about $1.8 \times 1.8 \times 1.8 \mathrm{~mm}^{3}$ recorded in each scan.

\subsection{Reconstruction and data processing}

The captured data were reconstructed by the standard ESRF tomography reconstruction software pyHST (High Speed Tomography in python version) [22] and included applying filtered back projection combined with a phase retrieval algorithm (Paganin et al. [23]). The reconstructed image volumes were first edited to diminish low-frequency gradients in grey values. This was performed by division of the original volume by the filtered volume using a 15 pixel radius 3-D Gaussian filter kernel implemented in the software ImageJ [24]. Subsequently, all phases were identified by segmentation based on a suitable selection of a 
global threshold. All image stacks were visualized and processed as volumes using the software VG-Studio MAX 2.1 by Volume Graphics. The different phases were labelled using different colours for visualisation.

\subsection{Analysis of data}

The data acquired at each temperature were evaluated using grey scale data sets and inspecting them manually by preparing 2D slices and searching for the phases contained. The software used allowed us to freely go through the entire imaged volume. Such slices are shown in Figs. 2 and 7. In parallel, 3D volumes of segmented data were used to analyse phase orientations in 3D and the connectivity of phases. Such images are given in Figs. 3, 4 and 6.

\section{Results}

\subsection{Phase separation during solidification}

The microstructural evolution during solidification was imaged by in-situ synchrotron X-ray tomography. The formation of $\alpha$-Al dendrites and eutectic Si could be observed but the formation of intermetallic phases was of primary interest. The images obtained were analysed particularly focussing on $\alpha, \beta, \gamma$ and $\delta$ intermetallic phases since these are the most commonly occurring phases in as-cast Al-10Si-0.3Fe (wt.\%) alloys containing impurities [25].

Figure 2 shows a sequence of vertical 2D slices extracted from the reconstructed 3D volumes depicting the events during solidification between $580^{\circ} \mathrm{C}$ and $549^{\circ} \mathrm{C}$. The first observed event after the onset of solidification is the appearance of primary $\alpha$-Al dendrites at $\sim 580{ }^{\circ} \mathrm{C}$ (Fig. 2a). $\alpha$-Al dendrites can be distinguished from the melt as their borders are slightly brighter. This is due to phase contrast in the images, not due to the very small difference in the absorption coefficient between the solid Al-rich dendrites and the melt, which is enriched in Si (slightly higher absorption) but also has a lower density (slightly lower absorption). The dewdrop-shaped objects arranged in a line in Fig. 2a appear to have grown from the oxide skin surface towards the centre of the sample. A similar observation of dendrite growth in another in-situ experiment has been reported for an Al-Cu alloy [26]. With temperature decreasing to $556{ }^{\circ} \mathrm{C}$, the $\alpha$ - $\mathrm{Al}$ dendrites grew and assumed the coarse appearance shown in Fig. 2b. In addition, Fig. 2b depicts the formation of eutectic Si phase (marked by an arrow). Again, dendrites and Si phase are visible against the background of the melt mainly due to phase contrast.

The eutectic Si phase started to grow at the bottom surface of the sample connected to the supporting alumina rod. At an even lower temperature of $553{ }^{\circ} \mathrm{C}$ and in close proximity to the surface oxide of the sample an accumulation of eutectic Al-Si phases is demonstrated in Fig. 2c1. Evolving eutectic Si forms plate-like structures that look like needles in the image slices 
(see arrows). The eutectic phases vary in appearance since the image grey scale is given by phase contrast. They may appear mixed dark and bright as in Fig. 2b and 2c1 or uniformly dark as in Fig. 2c2 and 2d2. Evidence that the eutectic Al-Si phases started to grow at the surface is clearly provided by Fig. 2c2 that shows a region near the surface (also at $553{ }^{\circ} \mathrm{C}$ ). A further event can be seen there: the phase appearing bright (marked by an arrow) is a $\delta$ phase that forms at the eutectic network near or at the oxide skin at $\sim 553{ }^{\circ} \mathrm{C}$. Iron-containing intermetallic phases appear brighter than the melt due to higher $\mathrm{X}$-ray attenuation (high absorption = bright; low absorption = dark).

The events observed in Fig. $2 \mathrm{~d} 1$ and $2 \mathrm{~d} 2$ at $\sim 552{ }^{\circ} \mathrm{C}$ are the formation of the $\beta$ phase and $\alpha$ or $\gamma$ phases, respectively. A coarse $\sim 400 \mu \mathrm{m}$ long $\beta$ phase (marked by arrow) is located between $\alpha$-Al dendrite arms as can be seen in Fig. $2 \mathrm{~d} 1$. Both segments belong to the same plate but an $\alpha$-Al dendrite (seen as a faint shadow) has prevented growth of $\beta$ at this location in the imaging plane. No eutectic Si was found in the surrounding area. In the region of Fig. $2 \mathrm{~d} 2 \mathrm{in}$ which eutectic Al-Si is located, small globular intermetallic phases appear bright with sizes ranging from $7 \mu \mathrm{m}$ to $10 \mu \mathrm{m}$. Some of these intermetallic phases are found in the melt without being surrounded by the eutectic Si phase and are identified as $\alpha$ and $\gamma$ phases based on the features described in our previous work [14]. The observations indicate that the growth of both $\alpha$ and $\gamma$ phases had already been completed at the current temperature $\left(552{ }^{\circ} \mathrm{C}\right)$. In Fig. $2 \mathrm{~d} 2$, slightly darker irregularly shaped regions correspond to liquid areas surrounded by the solidified phases. One of these liquid areas is marked by a circle and will be referred to as “cell”. Such "cells” will be discussed later. Finally, Fig. 2e shows the microstructure at $\sim 549{ }^{\circ} \mathrm{C}$ where the volume fraction of the intermetallic phases has reached a maximum. No significant changes of microstructure during the in-situ observation took place below this temperature indicating full solidification at this point.

Note that the full tomographic volumes were evaluated in 3D to describe and identify the phases and their surrounding areas and not only the 2D image slices shown in Fig. 2. In summary, phase formation was observed in the temperature range from $580{ }^{\circ} \mathrm{C}$ where the $\alpha$ $\mathrm{Al}$ dendrites start to grow down to $549{ }^{\circ} \mathrm{C}$ where the melt had completely solidified. $\alpha$-Al dendrites continued growing until $\sim 550{ }^{\circ} \mathrm{C}$ was reached, while solidification of eutectic Si was largely completed at this temperature and only a small fraction of the eutectic Si finished its growth at $\sim 549^{\circ} \mathrm{C}$.

Some of the $\alpha$-Al dendrites originated from the oxide skin of the sample during solidification. Other $\alpha$-Al dendrites nucleated in the interior of the sample. In contrast, eutectic Si preferentially grew from the bottom to the top along the oxide skin and also from the oxide skin towards the centre of the sample, see Fig. 2b and 2c1, but eutectic Si growth was not found to originate in the centre unlike $\alpha$-Al dendrites In this study, the eutectic Al-Si phase 
was found to originate from the oxide surface, in contrast to previous studies where the eutectic Al-Si phases nucleate at or near the surface of $\alpha$-Al dendrites $[9,27]$.

\subsection{Intermetallic phases}

Figure 3 displays a sequence of tomograms of the sample at $552{ }^{\circ} \mathrm{C}, 551{ }^{\circ} \mathrm{C}$ and $550{ }^{\circ} \mathrm{C}$ and highlights three independent groups of $\beta$ and $\delta$ phases. The sample contains a large number of both of these phases. They rarely exist alone and most of them are interconnected and appear as branched plates (as will be shown later, these branches were formed by collision of different plates). The intermetallic phases are classified into three groups based on the type of phase (identification described below) as indicated in Fig. 3b: Group 1: $\delta$ plates (dark green); group 2: $\beta$ plates (magenta) and group 3: further small $\delta$ plates (multiple colours). The oxide skin is represented in grey. Only the branched plates of group 1 form at or near the oxide skin. Examination of the evolution of the intermetallic plates of group 1 reveals that growth of the plates had almost finished at $\sim 552{ }^{\circ} \mathrm{C}$ (only some small changes are visible at $551{ }^{\circ} \mathrm{C}$ ). Therefore, this group will not be further analysed. In contrast, the branched plates in groups 2 and 3 appear to have nucleated above $\sim 552{ }^{\circ} \mathrm{C}$ and growth still occurred down to $550{ }^{\circ} \mathrm{C}$. The plates of these two groups finally impinge on each other at $\sim 551{ }^{\circ} \mathrm{C}$. Group 2 shows very clearly how the $\beta$ plate shown grows along the contour of an $\alpha$-Al dendrite. Moreover, a small pore has formed close to the $\beta$ phase (arrow in Fig. 3c).

Although visualizations of branched plates of both $\beta$ and $\delta$ phases were extracted from the tomograms, in the following only the $\delta$ phase will be analysed for each given temperature. $\mathrm{A}$ detailed analysis of the $\beta$ phase will be part of another study.

The $\beta$ and $\delta$ phases can be distinguished by their origin. The $\beta$ plate shown in Fig. 2e formed in the vicinity of $\alpha$-Al dendrites in the centre of the sample - neither touching the eutectic nor the oxide surface, see also Fig. 3. In contrast, $\delta$ plates were found to have their origin in a network of eutectic Al-Si phases or at oxide skins or pores.

We also analysed the structure of intermetallic phases by electron diffraction in the transmission electron microscope. These investigations confirm that both $\beta$ and $\delta$ phases are present in the samples after final cooling. As the samples prepared for TEM did not contain the original volume imaged by X-ray tomography any more, it is not possible to assign a structure identified by electron diffraction to a particular plate found in the tomograms.

\subsection{Evolution of $\delta$ phase}

The $\delta$ plates of group 3 (as marked in Fig. 3b) were extracted and are shown in Fig. 4 in a higher magnification. In 2D, the morphology of a $\delta$ phase appears needle-like while a 3D view reveals its true plate-like nature. Evolution of $\delta$ plates took place in a narrow 
temperature range: Nucleation occurred between $553{ }^{\circ} \mathrm{C}$ and $552{ }^{\circ} \mathrm{C}$, growth finished when reaching $551{ }^{\circ} \mathrm{C}$. Branched $\delta$ plates were formed within a very small temperature interval. The $\delta$ plates of group 3 appear much smaller than the $\beta$ plates of group 2 (see Fig. 3b). At $552{ }^{\circ} \mathrm{C}$ (see Fig. 4a) six independent and non-connected $\delta$ plates are visible. All six $\delta$ plates are separated from each other by at least a small gap. After further cooling down to $551{ }^{\circ} \mathrm{C}$ by just $1{ }^{\circ} \mathrm{C}$, four new plates were formed. In total ten plates were observed at this temperature that were then all interconnected (Fig. 4b), thus forming a branched structure. After further cooling to $550{ }^{\circ} \mathrm{C}$, no new $\delta$ plates were formed since solidification had almost completed (see Fig. 3c). Only a minute increase in thickness and lateral dimensions of the $\delta$ plates could be measured when approaching the lowest temperature.

The $\delta$ plates evolved only over a temperature interval of $2{ }^{\circ} \mathrm{C}\left(553{ }^{\circ} \mathrm{C}\right.$ to $551{ }^{\circ} \mathrm{C}$ in Fig. 3). Still, their growth rate can be estimated from the differences between two successive growth states. Rapid growth spurts of $\delta$ plates took place during the initial temperature step $\left(553{ }^{\circ} \mathrm{C}\right.$ to $552{ }^{\circ} \mathrm{C}$ ) immediately after nucleation, followed by a slower growth velocity during the second temperature step $\left(552{ }^{\circ} \mathrm{C}\right.$ to $\left.551{ }^{\circ} \mathrm{C}\right)$. The maximum and average recorded lateral growth rates of $\delta$ plates as well as the measured thickness growth rates for both temperature steps are presented in Table 2. The growth rates estimated in this study are all in good agreement with previous observations $[9,10]$.

\section{Discussion}

\subsection{Controversy of $\delta$ phase versus $\beta$ phase}

In addition to the $\beta$ phase, a further intermetallic phase was found in the Al-10Si-0.3Fe alloy during solidification, namely the $\delta$ phase. This appears plausible since the $\delta$ phase is the most frequently occurring intermetallic phase in as-cast commercial Al-10Si-0.3Fe alloy, at least at fast cooling rates [27]. In previous in-situ solidification experiments at slow cooling rates no $\delta$ phase but just $\beta$ phases were reported $[9,10]$. However, due to its plate-like morphology, which is similar to that of the $\beta$ phase, it is easy to wrongly identify the $\delta$ phase as $\beta$ phase.

As has been reported by Lu and Dahle [1] for an as-cast alloy with a Fe content similar to that in the current study ( $0.3 \mathrm{wt} . \% \mathrm{Fe}$ ), the $\beta$ phase forms via a ternary eutectic reaction $\mathrm{L} \rightarrow \alpha$-Al $+\mathrm{Al}-\mathrm{Si}+\beta-\mathrm{Al}_{5} \mathrm{FeSi}$ after the formation of eutectic Si. In fact, the phase formed here via a ternary reaction should be $\delta-\mathrm{Al}_{4} \mathrm{FeSi}_{2}$, because the $\delta$ phase is usually formed second during solidification, while the $\beta$ phase forms independently as the first primary phase. Liu et al. [28] reported two types of $\beta$ platelets, large pre-eutectic and smaller co-eutectic or post-eutectic $\beta$ corresponding to the precipitation sequence with respect to the Al-Si eutectic reaction. In the 
present study, large plates were found correspond to the $\beta$ phase while smaller ones correspond to the $\delta$ phase. The formation of $\beta$ in a binary reaction at a cooling rate of $0.33{ }^{\circ} \mathrm{C} / \mathrm{s}$ (comparable to the present study, $1{ }^{\circ} \mathrm{C} / \mathrm{s}$ ) in an alloy containing $0.8 \mathrm{wt} . \% \mathrm{Fe}$ was observed [21], which is in agreement with our results. In the present study, however, the plate-like intermetallic $\delta$ - $\mathrm{Al}_{4} \mathrm{FeSi}_{2}$ phase nucleates after the $\mathrm{Al}-\mathrm{Si}$ eutectic reaction.

It was proposed that $\delta$ is the dominant phase in alloys having high Si content and when applying high cooling rates. In contrast, $\beta$ is dominant in alloys with high Fe content and when low cooling rates are applied $[13,15,17]$. This conclusion is not supported by the present work because the $\delta$ phase was also found to form in an alloy with a high Si content and at low cooling rates.

No intermetallic $\beta$ phase was observed to nucleate and grow on the oxide skin of the sample, which is in contradiction to previous reports $[9,10]$. Based on the current 4D observation, $\alpha$ $\mathrm{Al}$ dendrites as well as $\beta$ phases nucleated well above the solidification temperature of the AlSi eutectic, the former at $580{ }^{\circ} \mathrm{C}$, the latter below as soon as Fe enrichment has reached a sufficient level. Due to limitations of spatial resolution, small $\alpha$ and $\gamma$ phases could rarely be discerned in these experiments. Therefore, formation of $\alpha$ and $\gamma$ phases will also not be discussed in the following.

\subsection{Nucleation of $\delta$ phase}

The $\delta$ plates observed by synchrotron X-ray tomography in this work were found to nucleate predominantly on the eutectic Si (as shown in Fig. 2c2). In few cases nucleation on inner surfaces of pores and the aluminium oxide located around or contained in the liquid cells was found (images not shown here).

These observations support the general assumption that the $\delta$ phase nucleates heterogeneously. It was previously proposed that the $\delta$ phase can nucleate on oxide bi-films [29]. Khalifa et al. [17] investigated a series of inclusions that may act as potential nucleation substrates and found that the $\delta$ phase can nucleate on inclusions such as $\mathrm{CaO}, \mathrm{TiB}_{2}$ or $\alpha-\mathrm{Al}_{2} \mathrm{O}_{3}$.

More generally, three conditions have to be satisfied simultaneously for the nucleation of $\delta$ phase, which is the second primary phase nucleated after $\beta$ [17]:

1) A critical solute concentration is required that corresponds to the composition of the phase to be nucleated.

2) the necessary nucleation temperature has to be reached,

3) an appropriate nucleation substrate has to be present. 
The eutectic is a potent nucleation site for the formation of the $\delta$ phase in this alloy since it is the experimentally predominant site. It is suggested that the build-up of a supersaturated solute (mainly $\mathrm{Fe}$ )-rich front is the essential condition irrespective of the nucleation site, eutectic, pores or oxides. The advancing solidifying eutectic Si phase would ideally satisfy the first condition by providing the necessary supersaturation as Fe is rejected from the solid.

\subsection{Growth of the $\delta$ phase}

The mechanism of $\delta$ phase evolution as derived from 4D tomography observations is explained schematically in Fig. 5. $\alpha$-Al dendrites (dark grey) and eutectic Si (green) grow during initial solidification and thereby fragment the remaining liquid into small isolated cells as marked by a circle in Fig. 2d2 and by a square in Fig. 5a. A "cell" is defined here as a small melt area surrounded by solid eutectic Al-Si phases or $\alpha$-Al dendrites. The evolution of the microstructure during solidification within the cells is depicted in four steps according to the nucleation and growth of $\delta$ plates. In the first step during solidification (Fig. 5b) of the eutectic Al-Si, the enclosed melt is enriched in Fe due to the rejection of Fe towards the solidliquid interfaces. The $\delta$ phase preferentially nucleates at the eutectic Si phase and grows inward, directed by the growth of the eutectic Al-Si that creates a moving zone of supersaturation in Fe and other solute atoms (Fig. 5b). More than one event at a time can be initiated simultaneously at each moving cell wall. The schematic drawings in Fig. 5 exhibit only 1-3 growing $\delta$ plates only for the sake of simplicity. Growth of the $\delta$ plate rapidly progresses radially towards the centre of the cell (see Fig. 5c). In the course of continuous solidification of the remaining melt in a cell, a new $\delta$ plate (marked by circle in Fig. $5 \mathrm{~b}$ ) might nucleate and also grow towards the centre of the cell. A further $\delta$ plate might also nucleate and grow in an inward direction (encircled $\delta$ plate in Fig. 5d) during progressing solidification. Finally, as illustrated in Fig. 5e, all these individual $\delta$ plates freely grow towards each other until the entire cell has solidified. This process, during which several branches of $\delta$ plates are produced, repeats until complete solidification of the melt. Interaction between $\delta$ plates and eutectic Si results in the formation of imprints such as the small indents on the olive-coloured $\delta$ plate in Fig. 4b. This can be explained by the fact that the growth in thickness of the $\delta$ plates follows the contours of the pre-existing eutectic Si.

Existing $\delta$ plates influence the environment of the remaining liquid due to local solute depletion around a plate. This influences the solidification process in such a way that $\delta$ plates do not nucleate on each other and form branches. Instead, $\delta$ plates that are formed at other locations impinge on other $\delta$ plates. In this way, complex branched structures can be generated as shown in Fig. 4 provided that no newly formed eutectic Al-Si blocks their growth and prevents them from impinging on other plates. 
The $\delta$ plates shown in Fig. 4 were analysed in more detail. Examples of growth and interaction of one, two or three separated $\delta$ plates are depicted in Fig. 6. As can be seen, the plates are branched at various angles. The angles greatly depend on the initial lateral growth direction of the $\delta$ plates from the outside to the inside within a cell and, therefore, individual plates are not related crystallographically. Eutectic Al-Si always surrounds a growing branch, both at the branching point and on the two sides of the plates, but occurrence of branching and plate orientation do not exclusively depend on physical obstructions unlike previously proposed in the literature $[9,10]$. Rather, plate orientations are mainly dictated by the liquid in nearby cells and the nucleation sites in the cells. However, branching is mainly determined by the orientation of the $\delta$ plates involved and blockages by the solidifying eutectic Al-Si. Figs. $6 a, 6 b$ and $6 \mathrm{c}$ show free growth of two, three or four individual $\delta$ plates growing towards each other with subsequent impingement at $551{ }^{\circ} \mathrm{C}$. Fig. $6 \mathrm{~d}$ shows a final impingement of three $\delta$ plates. Their growth was blocked by eutectic Al-Si during solidification.

Another example of branched $\delta$ plates is shown in Fig. 6e. At $551{ }^{\circ} \mathrm{C}$, one could suspect that the plates themselves acted as nucleation sites. However, careful observation does not support this mechanism of (auto-)nucleation. Therefore we conclude that the situation corresponding to Fig. 6e was formerly incorrectly interpreted as a new plate nucleating on an existing plate $[9,10]$. This incorrect interpretation is mainly due to the difficulty to observe the rapid growth and impingement of plates that sometimes extend beyond the field of view of the tomogram. The presence of some very thin $\delta$ plates seen faintly in 2D sections (not shown in Fig. 2) suggests that all three $\delta$ plates nucleated independently and then grew individually. However, the $\delta$ plate located in the middle of Fig. 6e (light purple) nucleated separately on the eutectic Si phase together with two thin $\delta$ plates. These two thin $\delta$ plates then merged and finally impinged on the $\delta$ plates on the left-hand side (light-magenta). After impingement, the middle $\delta$ plate (light purple) continued to grow slightly and at the same time the $\delta$ plate on the righthand side (light-cyan) nucleated on the eutectic Al phase and impinged on the side of the middle $\delta$ plate as analysis of the full 3D data sets shows.

$\delta$ plates were never found alone and were always observed to form branched configurations. Only one mechanism could be identified in the present study, namely the independent nucleation and growth and subsequent impingement of $\delta$ plates as can be seen in Fig. 6e. For $\beta$ plates, in contrast, two mechanisms were found to operate: One that is based on impingement of plates as for $\delta$, the other on the nucleation of new $\beta$ plates on existing $\beta$ plates [9]. The latter mode has never been observed for $\delta$ in the current experiment. 


\subsection{Bending of $\delta$ plates}

As reported in the literature $[9,10]$ thin evolving $\beta$ plates can undergo deformation, bending or fracture during growth, which is a result of physical interactions with contacting dendrites. Deformation of $\delta$ plates due to internal strains and frequent contact with eutectic Al-Si and solidified $\alpha$-Al dendrites has also been observed in the present study. A small movement of the outer oxide skin and of the dendrites can also occur during shrinkage of the sample upon solidification. This can locally change the growth orientation of a $\delta$ plate.

The deformation process of $\delta$ plates is observed in Fig. 6f. Accordingly, the upper $\delta$ plates (orange and the purple-pink) initially formed as one highly curved $\delta$ plate. Some of the $\delta$ plates are not visible in the segmented 3D renderings, but they are seen in Fig. 7a in 2D slices. During growth the middle part of the curved $\delta$ plate impinged on the existing $\delta$ plate (blue) in Fig. 6f. Because of this impingement and the desire of these $\delta$ plates to grow straight, the original curved $\delta$ plate evolved into three segments. The middle part grew parallel to the blue plate (Fig. 6f), whereas the two side parts forming an angle with the middle part continued to grow slightly. It follows from the observation of unsegmented 3D images (not shown) that no eutectic Al-Si was involved during this straightening process. The deformation process of $\delta$ plates is seen very clearly in 2D slices of tomograms as shown in Fig. 7a. A corresponding schematic explanation is given in Fig. 7b below the 2D slices. According to the current observations, no new $\delta$ plate nucleated directly on the existing $\delta$ plates and no eutectic Al-Si phase directly nucleated on the $\delta$ plates. A curved $\delta$ plate can straighten itself when it grows closer to an adjacent straight $\delta$ plate. As follows from Fig. 6f and 7, this happened here because the curved $\delta$ plate was pinned by the already existing and newly formed eutectic AlSi.

\section{Summary}

The evolution of the microstructure in an Al-10Si-0.3Fe (wt.\%) alloy was characterized by insitu synchrotron X-ray tomography during solidification.

Nucleation and growth of the $\delta$ phase is explained via a "cell" formation mechanism during solidification. Small liquid areas ("cells") gradually undergo solidification during which $\delta$ plates nucleate on the cell walls and then grow towards their centre. At each stage of solidification new $\delta$ plates may nucleate and grow. This process repeats itself and is eventually either blocked by another $\delta$ plate or by newly formed eutectic Al-Si phases. Branched $\delta$ plates are always observed, but branches are generated only by impingement of plates rather than via a nucleation mechanism in which new $\delta$ plates nucleate on existing $\delta$ 
plates. The critical solute concentration is the key factor for the nucleation of the $\delta$ phase rather than the potency of the substrate. Nucleation on the eutectic Si is the main cause for growth of the $\delta$ phase since the solute concentration is fixed in this alloy. Since the formation of the $\delta$ phase mainly occurs during the eutectic Al-Si reaction, interaction among the eutectic and the $\delta$ phase is another key factor influencing the formation of the $\delta$ phase.

The knowledge we gain from this work suggests a promising processing route for improving the mechanical properties of such alloys: The intermetallic $\delta$ phase can be largely refined and fragmented by accelerating the formation of the fine Al-Si eutectic and thus enhancing their density. 


\section{References}

[1] L. Lu, A.K. Dahle, Iron-rich intermetallic phases and their role in casting defect formation in hypoeutectic Al-Si alloys, Metall. Mater. Trans. A 36A (2005) 819-835

[2] A. Gorny, J. Manickaraj, Z. Cai, S. Shankar, Evolution of Fe based intermetallic phases in $\mathrm{Al}-\mathrm{Si}$ hypoeutectic casting alloys: Influence of the $\mathrm{Si}$ and $\mathrm{Fe}$ concentrations, and solidification rate, J. Alloys \& Comp. 577 (2013) 103-124

[3] C.M. Dinnis, J.A. Taylor, A.K. Dahle, As-cast morphology of iron-intermetallics in Al-Si foundry alloys, Scripta Mater. 53 (2005) 955-958

[4] A.M. Samuel, A. Pennors, C. Villeneuve, F.H. Samuel, H.W. Doty, S. Valtierra, Effect of cooling rate and Sr-modification on porosity and Fe-intermetallics formation in Al-6.5\% Si3.5\% Cu-Fe alloys. Int. J. Cast, Met. Res. 13 (4) (2000)231-253

[5] P. Ashtari, H, Tezuka, T, Sato, Influence of Sr and Mn additions on intermetallic compound morphologies in Al-Si-Cu-Fe cast alloys. Mater. Trans. 44 (2003) 2611-2616

[6] A.M. Samuel, F.H. Samuel, C. Villeneuve, H.W. Doty and S. Valtierra, Effect of trace elements on $\beta$-Al5FeSi characteristics, porosity and tensile properties of Al-Si-Cu (319) cast alloys. Int. J. Cast Metals Res. 14 (2001) 97-120

[7] M. Timpel, N. Wanderka, R. Grothausmann, J. Banhart, Distribution of Fe-rich phases in eutectic grains of Sr-modified Al-10wt\%Si-0.1wt\% Fe casting alloy, J. Alloy \& Comp. 558 (2013) 18-25

[8] J. Wang, M. Li, J. Allison and P.D. Lee, Multiscale modelling of Fe content in a Al-Si-Cu alloy on the size distribution of intermetallic phases and micropores, J. AP, 107 (2010) 061804

[9] C. Puncreobutr, A.B. Phillion, J.L. Fife, P. Rockett, A.P. Horsfield, P.D. Lee, In-situ quantification of the nucleation and growth of Fe-rich intermetallics during $\mathrm{Al}$ alloy solidification, Acta Mater. 79 (2014) 292-303

[10] S. Terzi, J.A. Taylor, Y.H. Cho, L. Salvo, M. Suéry, E. Boller, A.K. Dahle. In-situ study of nucleation and growth of the irregular $\alpha-\mathrm{Al} / \beta-\mathrm{Al}_{5} \mathrm{FeSi}$ eutectic by $3-\mathrm{D}$ synchrotron $\mathrm{X}$-ray microtomography, Acta Mater. 58 (2010) 5370-5380

[11] A. Couture, Iron in aluminum casting alloys - A literature survey. AFS Int. J. Cast. Met. 6 (1981) 9-17

[12] L. Bäckerud, G. Chai, J. Tamminen, Solidification Characteristics of Aluminum Alloys, Foundry Alloys, vol. 2, AFS/Skanaluminum (1990) 71-84 
[13] W. Khalifa, F.H. Samuel, J.E. Gruzleski, Iron intermetallic phases in the corner of the Al-Si-Fe system, Metall. Mater. Trans. A 34A (2003) 807-825

[14] J.M. Yu, N. Wanderka, G. Miehe, J. Banhart, Intermetallic phases in high-purity Al10Si-0.3Fe cast alloys with and without Sr modification studied by FIB tomography and TEM, Intermetallics, 72 (2016) 53-61

[15] Y.S. Choi, J.S. Lee, W.T.Kim, H.Y. Ra, Solidification behaviour of Al-Si-Fe alloys and phase transformation of metastable intermetallic compound by heat treatment, J. Mater. Sci. 34 (1999) 2163-2168

[16] M.V. Kral, P.N.H Nakashima, D.R.G. Mitchell, Electron Microscope studies of Al-Fe-Si intermetallics in an Al-11Pct Si alloy, Metall. Mater. Trans. A 37A (2006) 1987-1997

[17] W. Khalifa, F.H. Samuel, J.E. Gruzleski, H.W. Doty, S. Valtierra, Nucleation of Feintermetallic phases in the Al-Si-Fe alloys, Metall Mater Trans A, 36A (2005) 1017-1032

[18] M. Timpel, N. Wanderka, B.S. Murty, J. Banhart, Three-dimensional visualization of the microstructure development of Sr-modified Al-15Si casting alloy using FIB-EsB tomography, Acta Mater. 58 (2010) 6600-6608

[19] J. Wang, P.D. Lee, R.W. Hamilton, M. Li, J. Alison, The kinetics of Fe-rich intermetallic formation in aluminium alloys: In situ observation. Scripta Mater. 60 (2009) 516-519

[20] M.V. Kral, H.R. McIntyre, M.J. Smillie, Identification of intermetallic phases in a eutectic Al-Si casting alloy using electron backscatter diffraction pattern analysis, Scripta Mater. 51 (2004) 215-219

[21] S. Terzi, L. Salvo, M. Suery, A.K. Dahle, E. Boller, Coarsening mechanisms in a dendritic Al-10\% Cu alloy, Acta Mater. 58 ( 2010) 20-30

[22] Reconstruction program performing by pyHST (High Speed Tomography in python version) software. http://www.esrf.eu/UsersAndScience/Experiments/Imaging/ID19/ micro tomography/computing duringexperiment/toto

[23] D. Paganin, S.C. Mayo, T.E. Gureyev, P.R. Miller, S.W. Wilkins, Simultaneous phase and amplitude extraction from a single defocused image of a homogeneous object, $\mathrm{J}$. Microscopy 206 (2002) 33-40. doi:10.1046/j.1365-2818.2002.01010.x

[24] Software ImageJ, https://imagej.nih.gov/ij/docs/faqs.html\#cite 
[25] J.M. Yu, Ph.D Thesis, Formation of intermetallic phases in Al-10Si-0.3Fe based alloys, 2016

[26] N. Limodin, L. Salvo, E. Boller, M. Suéry, M. Felberbaum, S. Gailliègue, K. Madi, Insitu and real-time 3-D microtomography investigation of dendritic solidification in an Al-10 wt.\% Cu alloy, Acta Mater. 57 (2009) 2300-2310

[27] R. H. Mathiesen, L. Arnberg, Y. Li, V. Meier, P. Schaffer, I. Snigireva, A. Snigirev, A.K. Dahle. X-Ray videomicroscopy studies of eutectic Al-Si solidification in Al-Si-Cu, Metall. Mater. Trans. A 42A (2011) 170-180

[28] L. Liu, A.M.A. Mohamed, A.M. Samuel, F.H. Samuel, H.W. Doty, S. Valtierra, Precipitation of $\beta-\mathrm{Al}_{5} \mathrm{FeSi}$ phase platelets in Al-Si based casting alloys. Metall. Mater. Trans. A 40A (2009) 2457-2469

[29] X. Cao, J. Campbell, The nucleation of Fe-rich phases on oxide films in Al-11.5Si0.4Mg cast alloys, Metall. Mater. Trans. A 34A (2003)1409-1420 


\section{Figure Captions}

Figure 1. In-situ X-ray synchrotron tomography set-up at beamline ID 19 of the ESRF, Grenoble, France. 1: furnace; 2: windows in furnace; 3: rotation stage; 4: alumina rod (sample holder); 5: optics and 6: PCO-Dimax CMOS camera.

Figure 2. Vertical 2D slices extracted from tomograms obtained during cooling and solidification. Various phases that have formed during solidification at different temperatures are shown: (a) $\alpha-\mathrm{Al}$ dendrites at $580{ }^{\circ} \mathrm{C}$ (arrow); (b) the eutectic Al-Si (marked by an arrow) at $556{ }^{\circ} \mathrm{C}$; (c1) the eutectic Al-Si (marked by arrows) forming along the bottom and the oxide skin of the sample towards the centre at $553^{\circ} \mathrm{C}$; (c2) a $\delta$ phase (marked by an arrow), also at $553^{\circ} \mathrm{C}$; (d1) a $\beta$ phase (marked by arrows) at $552{ }^{\circ} \mathrm{C}$; (d2) $\alpha$ or $\gamma$ phases (bright, marked by arrows) also at $552{ }^{\circ} \mathrm{C}$ and a liquid “cell” marked by a circle; (e) state after approaching the end of phase separation at $549^{\circ} \mathrm{C}$. Slices were extracted from near the surface (c2) or from near the middle of the sample (all others) to visualize the features of interest.

Figure 3. Visualization of the evolution of $\beta$ and $\delta$ plates at (a) $552{ }^{\circ} \mathrm{C}$, (b) $551{ }^{\circ} \mathrm{C}$ and (c) $550{ }^{\circ} \mathrm{C}$. Groups of various intermetallic phases are shown: Group 1, $\delta$ plates (dark green); group 2, $\beta$ plates (magenta) and group 3, further small $\delta$ plates (multiple colours). Group numbers are given in (b). The oxide skin in the background is visualized in grey and eutectic $\mathrm{Al}$ and $\mathrm{Si}$ as well as $\alpha$-Al dendrites have been made transparent. Small pore formed close to the $\beta$ phase is marked by arrow in (c).

Figure 4. $\delta$ plates as extracted from Fig. 3 (group 3). Formation and grow of independent $\delta$ plates (a) six non-connected plates are visible at $552{ }^{\circ} \mathrm{C}$, (b) at $551^{\circ} \mathrm{C}$ four new plates have been added. All plates are interconnected. Each colour corresponds to an individually nucleated plate.

Figure 5. Schematic representation of the formation of $\delta$ plates in Al-10Si-0.3Fe alloy: (a) growing eutectic $\mathrm{Al}-\mathrm{Si}$ and $\alpha$-Al dendrites fragment melt into cells during solidification. Microstructure evolution within a cell is divided into 4 steps according to nucleation and subsequent grow of $\delta$ plates (see numbering): (b) first step: close up view of the region marked by a red box in (a) showing a $\delta$ plate at the onset of growth; (c) second step: new $\delta$ 
plate (marked by circle) nucleates and grows on the newly solidified eutectic Al-Si phase; (d) third step: a further $\delta$ plate (marked by circle) growth upon progressing solidification of the liquid; (e) forth step: solidification is completed.

Figure 6. Complex growth and interaction of particular $\delta$ plates extracted from Fig. 4. Each colour corresponds to an individual plate.

Figure 7. Deformation process of $\delta$ plates observed in vertical 2D slices of tomograms: (a) at $552{ }^{\circ} \mathrm{C}$ : highly curved $\delta$ plate; at $551{ }^{\circ} \mathrm{C}$ : curved $\delta$ plate has evolved into three segments; and at $549{ }^{\circ} \mathrm{C}$ : middle part has grown parallel to the already present $\delta$ plate. At the lower temperatures, the two side parts grow at an angle to the middle part.

(b) Schematic representations of deformation process corresponding to a).

\section{Tables}

Table 1. Chemical composition of the Al-10Si-0.3Fe alloy. The main elements $\mathrm{Al}, \mathrm{Si}$ and Fe are given in \%, impurities in ppm, both by mass.

Table 2. Growth rates of $\delta$ plates after nucleation in two different temperature ranges.

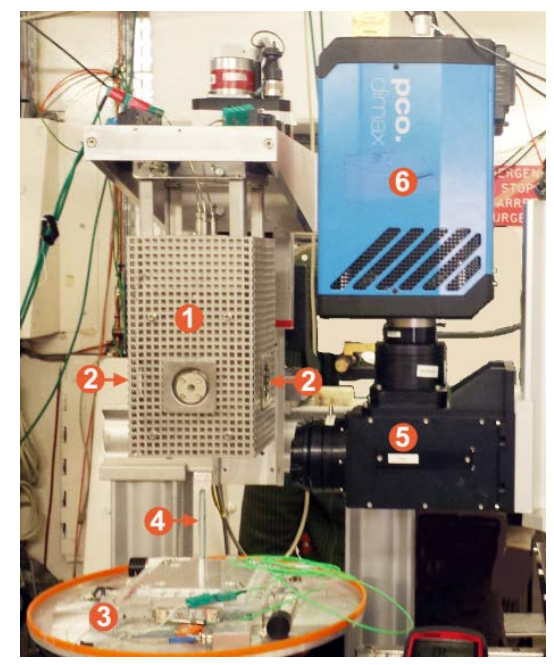

Fig. 1 

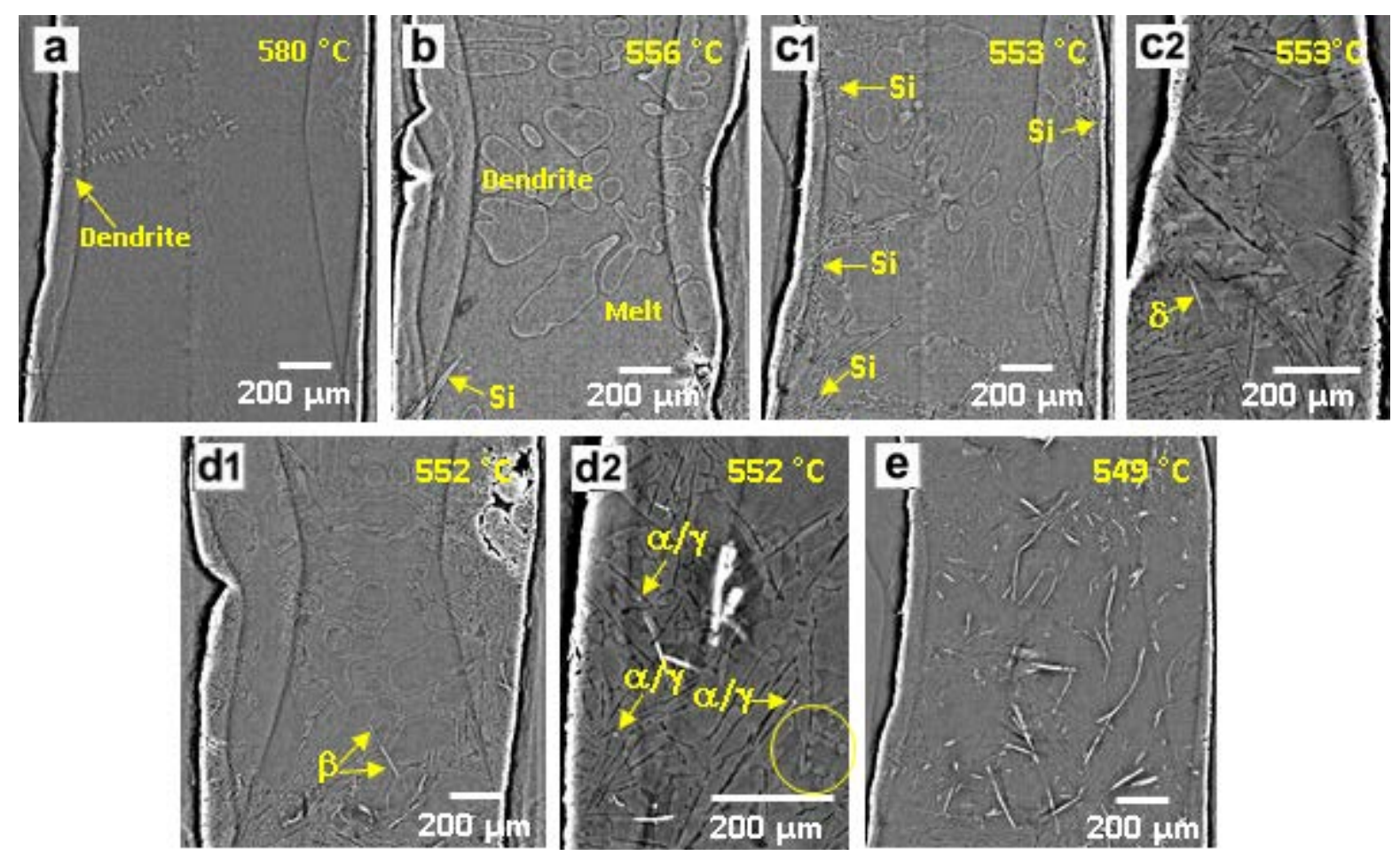

Fig. 2
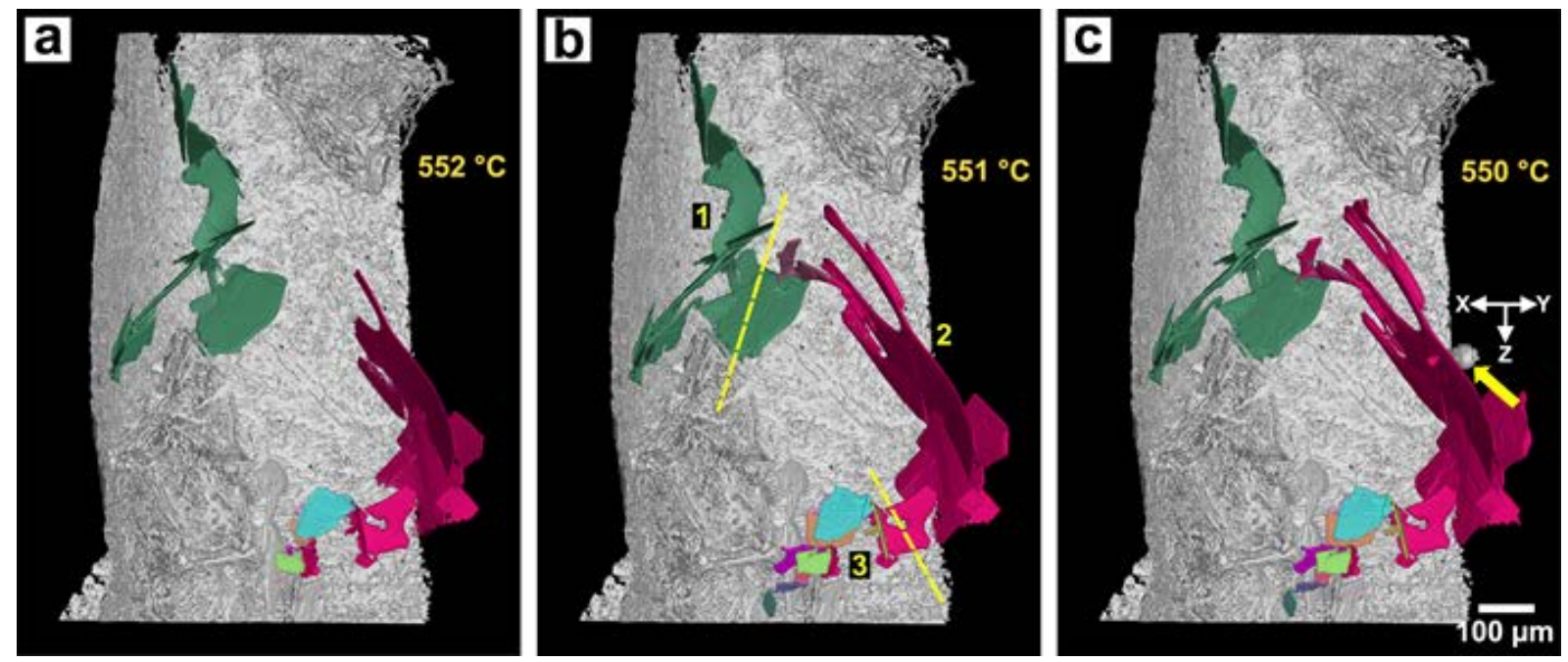

Fig. 3 


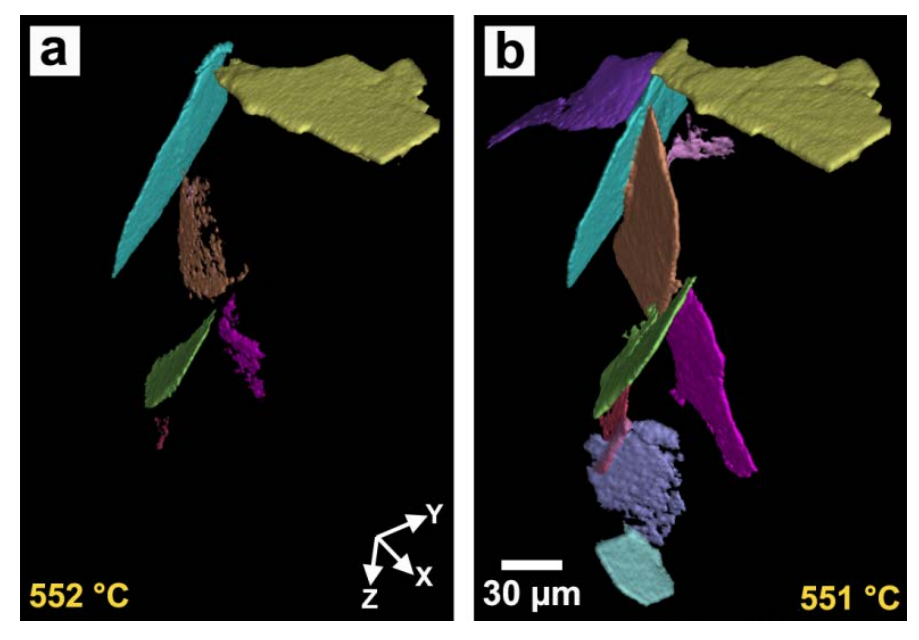

Fig. 4

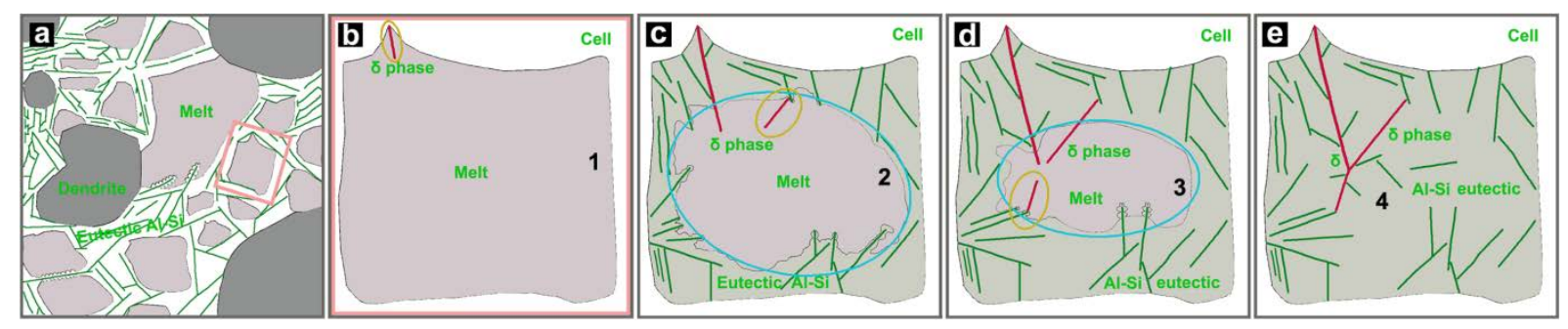

Fig.5 

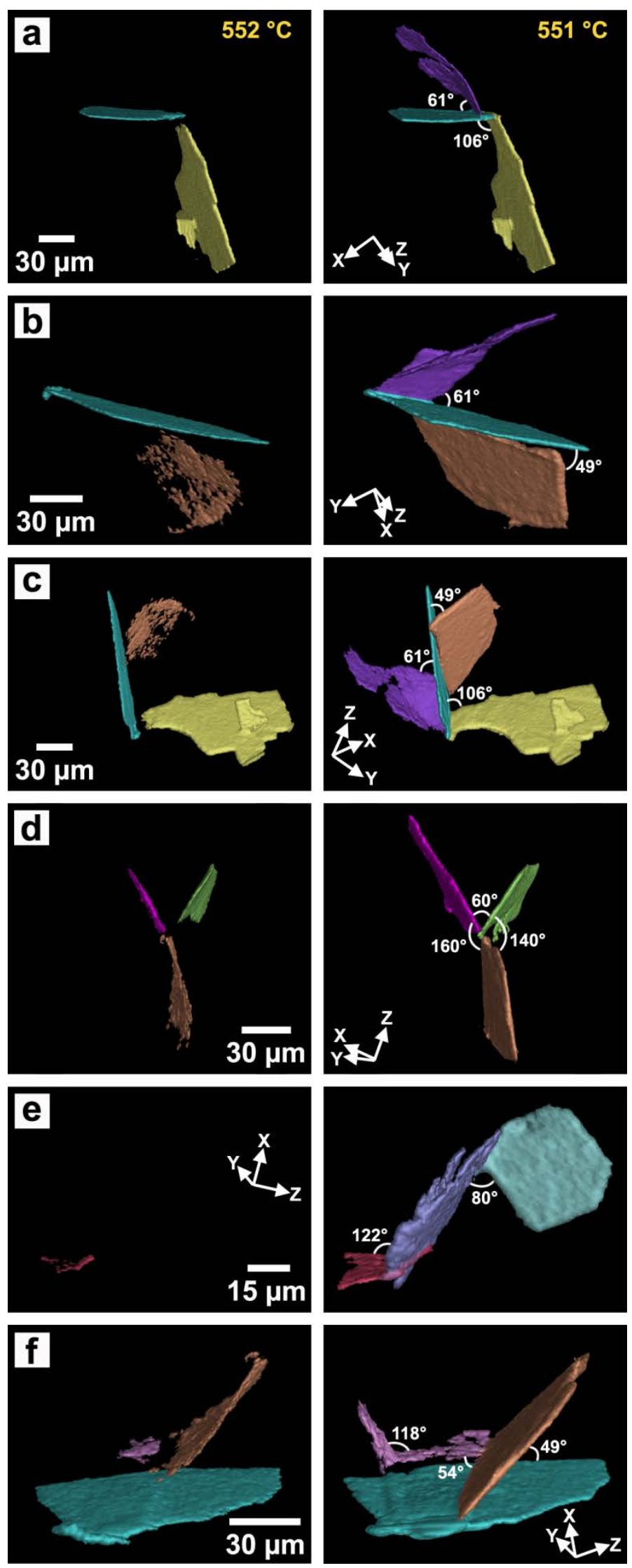

Fig. 6 


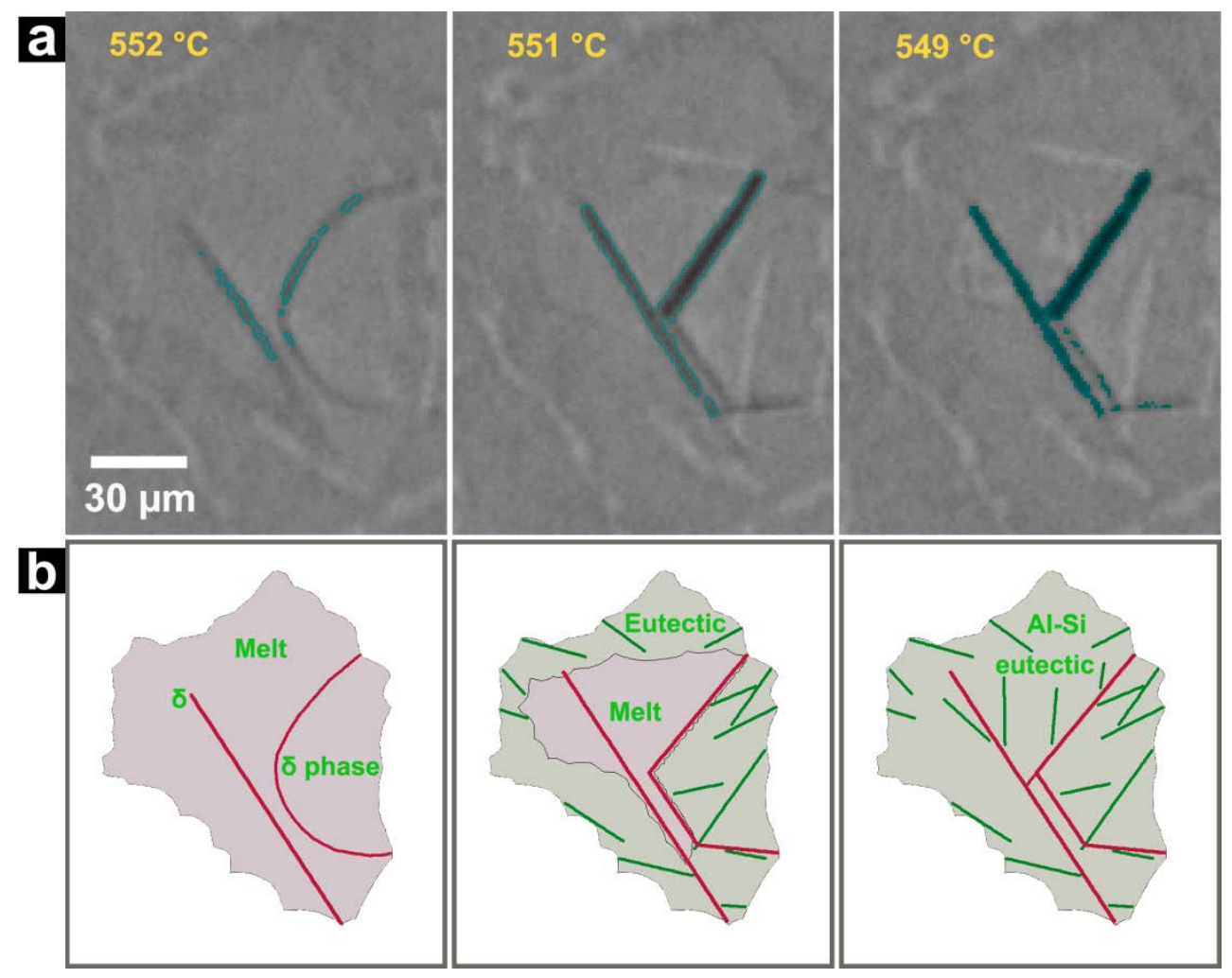

Fig. 7

\section{Tables}

Table 1

\begin{tabular}{|c|c|c|c|c|c|c|c|c|c|c|c|c|c|c|}
\hline \multirow{3}{*}{ Alloy } & Al & Si & $\mathrm{Fe}$ & $\mathrm{Cu}$ & Mn & $\mathrm{Mg}$ & $\mathrm{Ni}$ & $\mathrm{Zn}$ & $\mathrm{Ti}$ & $\mathrm{Cr}$ & V & Ga & $\mathbf{P}$ & $\mathrm{Sr}$ \\
\hline & \multicolumn{3}{|c|}{ wt. \% } & \multicolumn{11}{|c|}{$\mathrm{ppm}$} \\
\hline & 89.8 & 9.9 & 0.3 & 16 & 16 & 4 & 49 & 96 & 21 & 9 & 65 & 92 & 7 & $<1$ \\
\hline
\end{tabular}

Table 2

\begin{tabular}{c|cc|cc}
$\begin{array}{c}\text { Temperature } \\
\text { range } \\
\left({ }^{\circ} \mathrm{C}\right)\end{array}$ & $\begin{array}{c}\text { Max. lateral } \\
\text { growth rate } \\
(\mu \mathrm{m} / \mathrm{s})\end{array}$ & $\begin{array}{c}\text { Average lateral } \\
\text { growth rate } \\
(\mu \mathrm{m} / \mathrm{s})\end{array}$ & $\begin{array}{c}\text { Max. thickening } \\
\text { rate } \\
(\mu \mathrm{m} / \mathrm{s})\end{array}$ & $\begin{array}{c}\text { Average } \\
\text { thickening } \\
\text { rate }(\mu \mathrm{m} / \mathrm{s})\end{array}$ \\
\hline $553-552$ & 2.35 & 1.22 & 0.1 & 0.07 \\
$552-551$ & 0.95 & 0.33 & 0.05 & 0.025
\end{tabular}

